\title{
Propagation Measurements of a 4G LTE Network in Lagoon Environment
}

\author{
Agbotiname Lucky Imoize*, Tolulope Emmanuel Ogunfuwa \\ Department of Electrical and Electronics Engineering, University of Lagos, Akoka Lagos, Nigeria.
}

\begin{abstract}
Analysis of predicted and measured path loss over a Lagoon environment is presented. Propagation measurements were carried out at $1800 \mathrm{MHz}$, within a quarter of a year (May to August 2017) using Huawei Technologies drive test equipment. Measured data comprising of the received signal strength was taken for the initial measurements, measurements after first month, measurements after second month, and measurements after the third month. Measured path loss was compared with predictions made by free-space, log-distance, two-ray, COST 231Hata, and Stanford University Interim (SUI) models. The COST-231 Hata model showed the most accurate performance with root mean square errors (RMSEs) of $10.03 \mathrm{~dB}, 12.38 \mathrm{~dB}, 17.59 \mathrm{~dB}$, and $7.67 \mathrm{~dB}$ for the initial measurements, measurements after first month, measurements after second month, and measurements after third month, respectively. In order to achieve a more accurate prediction, the COST 231 Hata model was optimized using the least square algorithm. The optimized model showed improved signal prediction with RMSEs of $7.90 \mathrm{~dB}, 9.28$ $\mathrm{dB}, 14.82 \mathrm{~dB}$ and $5.28 \mathrm{~dB}$, respectively. The average RMSEs of the optimized COST 231 Hata model showed 9.32 $\mathrm{dB}$ compared with $11.92 \mathrm{~dB}$ predicted by the actual COST 231 Hata model. This accounts for about $21.81 \%$ improvements over the existing COST 231 Hata model. Therefore, the optimized COST 231-Hata model could be used to characterize radio channels in the investigated environments.
\end{abstract}

KEYWORDS: Propagation measurements, 4G LTE network, Lagoon environment, Pathloss models, Root mean squared error, Least square algorithm.

[Received April 16, 2017; Revised June 26, 2018; Accepted October 20, 2018]

Print ISSN: 0189-9546 | Online ISSN: 2437-2110

\section{INTRODUCTION}

\section{A. Overview}

Pathloss prediction has been identified as one of the most important considerations in designing and implementing a fourth Generation (4G) Long Term Evolution (LTE) network for substantial gains in spectral efficiency (Atanasov and Kissovski, 2013). It is possible to estimate path loss propagation in a mobile environment based on simulation of empirical propagation models. For optimum performance, some of these models have been optimized for the environment of interest (Saxena and Sindal, 2018). However, simulationbased models are not able to predict the propagation environment with high accuracy as desired. Therefore, there is a need for measurement-based propagation models for near precise prediction of the propagation environment (Sharma et al., 2016).

With the ever-increasing demand for wireless and mobile communication services, there has been a need to provide quality data and network services by mobile services providers. Providing quality service requires proper and careful network planning to circumvent the challenges of network congestion and interference. Propagation models have shown to be useful tools that can help in proper network planning, and they provide a means of making estimations and

*Corresponding author: aimoize@ unilag.edu.ng predictions of network coverage in a particular location, which in turn help service providers, make a cost effective network plan. Several studies on propagation pathloss have been reported and the results of these investigations have led to a number of conclusions. Some of these models work well for the environments for which they have been designed, and the performance of propagation models is dependent on the geography or topology of the locations where they are applied. Many interests have been shown in the area of path loss predictions on land, which have consequently led to the development of some well-known propagation models such as the Stanford University Interim (SUI), COST 231-Hata and the ECC-33 models (Abhayawardhana et al., 2005). However, very few reports have discussed pathloss measurements and modeling in water environments, and the results reported in this paper will add to the existing literature.

There is no doubt that the performance of a typical wireless communication system depending on where it is deployed come with some challenges. In Nigeria, wireless mobile services have been characterized by frequent call congestion, rapid network outage and unreliable internet connectivity. Poor path loss characterization has been identified as a major cause of this problem. Path loss characterization makes it possible to determine path loss models that are most accurate for the environment of interest. doi: http://dx.doi.org/10.4314/njtd.v16i1.1 
While efforts have been made to solve this problem, available reports (Ajose and Imoize, 2013; Ibhaze et al., 2017; Imoize and Dosunmu, 2018) show that focus is mainly on terrestrial radio waves propagation. It is very difficult to find detailed reports on pathloss measurements and modeling in Lagoon environments. There is no doubt that radio signal propagation is worse in water medium and we have not been able to identify any comprehensive report on path loss characterization for a 4G LTE network in a Lagoon setting. In order to fill this gap, this study is focused on path loss characterization in a typical Lagoon environment in Lagos Nigeria, with a goal to determining the most well performed model for quality signal prediction in the environment.

\section{B. Survey of Related Works}

In the quest to improve broadband services, wireless mobile network planners, and design engineers have reported several propagation models. Knowing the influence of pathloss on the effective propagation of network signals, these models have been utilized by network engineers and designers to make reasonable propagation loss predictions, which in turn aid network design, and planning (Ajose and Imoize, 2013). These models include free space model (Rappaport, 1996; Seybold, 2005), Stanford University Interim (SUI) model (Abhayawardhana et al., 2005), Okumura-Hata model (Hata, 1980), Lee model (Aragon-Zavala, 2008), Ericsson model (Milanovic et al., 2007), Weissberger model (Weissberger, 1982; Seybold, 2005), COST 231-Hata model (Seybold, 2005; Abhayawardhana et al., 2005; Aragon-Zavala, 2008), Erceg model (Erceg et al., 1999), and ECC-33 model (Abhayawardhana et al., 2005; Philips et al., 2013). Here, it should be noted that a great number of these models have been tested with impactful results.

Zhou et al., (2006) reported a study on the characterization of radio path loss in seaport environment for WiMAX applications at an operating frequency of $5.8 \mathrm{GHz}$. Radio pathloss measurements were taken and compared with the free space propagation model. Results showed that the path loss properties were close to free space and become clearer with higher transmitter antenna height.

Milanovic et al. (2007) carried out a study on the comparison of propagation models accuracy for WiMAX at an operating frequency of $3.5 \mathrm{GHz}$, by considering both non-lineof-sight (NLOS) and line-of-sight (LOS) conditions. Measured data was compared with the SUI model, COST 231-Hata model, Macro model, and Ericsson 9999 model. Here, the investigated environments were divided into urban and suburban, the standard deviation of the prediction error for NLOS condition was found to be lowest for the SUI model, and the Macro model showed the lowest standard deviation error for LOS propagation conditions.

Sharma and Singh (2010) presents a comparative analysis of path loss models with field-measured data. The models include Stanford University Interim (SUI) model, Hata model, COST231 Extension to Hata model, Walfisch - Bertoni model, and the ECC-33 model. Measurements was conducted in three different environments; rural, suburban and urban at $900 \mathrm{MHz}$ and $1800 \mathrm{MHz}$. Results showed that the COST 231-Hata model and the SUI model showed the most accurate predictions in the urban and sub urban environments, respectively.

Reyes-Guerrero et al., (2011) presents buoy-to-ship experimental measurements over sea at $5.8 \mathrm{GHz}$ near urban environments. Measurements were carried out by transmitting a $30 \mathrm{dBm}$ continuous wave $(\mathrm{CW})$ from an antenna installed on a buoy and receiving this signal in a receiver installed aboard a ship. The focus is on large-scale characteristics in NLOS and LOS paths. Measured data were compared with the two-ray, and free space propagation models. It was observed that the two-ray model fitted measured large-scale path loss reasonably well when LOS condition remains. In addition, the received signal suffers high additional losses when LOS condition does not remain. The losses relate to the higher values of the standard deviation that were found in NLOS conditions.

Yee Hui et al., (2014) reported a near sea-surface propagation measurements and modeling. Measurement campaign was conducted, and the measured data were weighed alongside the free space model and the two-ray path loss model. It was concluded that the prediction ability of two-ray model became poor when the propagation distance increased. In order to solve this problem, the two-ray path loss model was optimized, and the optimized model was found to be very promising for the investigated environment.

Wang et al. (2015) investigated the scattering phenomena of the propagation channel on the Baltic Sea, at an operating frequency of $5.2 \mathrm{GHz}$. Scattering of the signal due to the roughness of the sea surface as well as the validity of the Karasawa model (Karasawa, 1997) was studied. This is because the model has mostly been used for carrier frequency below $3 \mathrm{GHz}$. Here, a channel sounder measurement where the transmitter antenna was mounted on a ship and the receiver antenna was located on land was used. The Karasawa model was used to study the scattering effect, and it was concluded that the model showed validity for the propagation of radio waves at the carrier frequency of $5.2 \mathrm{GHz}$.

In this paper, measured pathloss is compared with five pathloss models; free space pathloss (Rappaport, 1996; Seybold, 2005; Aragon-Zavala, 2008; Ubom et al., 2011), logdistance model (Seidel and Rappaport, 1992), two-ray model (Philips et al., 2013), SUI model (Abhayawardhana et al., 2005; Sulyman et al., 2016), and COST 231 Hata model (Seybold, 2005; Aragon-Zavala, 2008). The goal is to identify and optimize the most accurate model for improved performance in the investigated environment and validate the accuracy of the optimized model for improved pathloss prediction in the tested environments. It is expected that the optimized model would be of immense benefits to network services providers to further improve on network coverage and capacity, thereby enhancing the quality of services for end users.

\section{A. Experimental Setup}

\section{MATERIALS AND METHOD}

The measurement of signal strength was obtained by conducting a Drive Test (DT) using a global positioning system (GPS) module, 4G LTE Modem, LTE software, and a computer system. The modem used is a Huawei E392 4G LTE modem with a frequency range of 800/900/1800/2100/2600 
MHz. It has LTE download speed up to $100 \mathrm{Mbit} / \mathrm{s}$ and LTE upload speed up to $50 \mathrm{Mbit} / \mathrm{s}$. The LTE software, which is the Genex probe, is installed on the computer for recording DT data and post processing. The GPS module is connected to the computer for navigation and for monitoring the location of base stations. As the DT vehicle drives past different base stations, the reference signal received power (RSRP) for every LTE evolved node B (eNodeB) sectors, is measured and recorded by the LTE software on the computer system. The GPS navigates the DT, and the mean of the RSRP is determined by taking the mean values of the received power measured from the base stations. The experimental setup is as shown in Fig. 1.

\section{B. Measurements Procedure}

The investigated environment is located around a body of water popularly referred to as the University of Lagos (UNILAG) Lagoon in Lagos, Nigeria. The Lagoon front has a little vegetation and a few trees around located on Latitude $6^{\circ} 31.228^{\prime} N$ and Longitude $3^{\circ} 24.044^{\prime} E$ with an altitude of $12 \mathrm{ft}(3.66 \mathrm{~m})$ above sea level. The pictorial view of the Lagoon environment is as shown in Fig. 2. The Lagoon provide a sizeable body of water required for the study. A survey of the environment was conducted, and a measurement plan was developed with respect to the location of the fixed LTE evolved Node B (eNodeB) in the environment. The plan helps to locate measurement points while considering both LOS and NLOS scenarios.

Propagation measurements were taken at $1800 \mathrm{MHz}$ using Huawei Technologies Genex probe V3.16 in a Lagoon environment. Starting from a reference distance $d_{0}$ from the fixed eNodeB, measurements were taken at a specified distance (starting from about $0.2 \mathrm{~km}$ ) interval between the mobile antenna and the transmitter over a propagation distance of $1 \mathrm{~km}$ at a near constant mobile antenna height of $1.5 \mathrm{~m}$, throughout the measurements campaign. The GPS was used to accurately track the location of measurement equipment and the coordinates of the eNodeB.

Measurements were taken for a period of four months comprising of initial measurements, measurements after one month, measurements after two months, and measurements after three months. Measured data comprising of the reference signal received power (RSRP) in $\mathrm{dBm}$ obtained for each measurement was extracted using MapInfo professional tool, and the results are analyzed using data statistics in MATLAB. The measured RSRP was converted to pathloss, and the root mean square error was used to determine the best-fit model for the measured data in the investigated environment. The bestfit model was selected, and optimized for improved signal prediction, and the optimization was carried out using least squares algorithm. Further information on the measurement procedure and modeling parameters are available in a recent paper (Imoize and Dosunmu, 2018).

\section{Propagation models}

The propagation models selected for comparison with measured data are briefly described as follows. These models were chosen as appropriate and valid for the $1800 \mathrm{MHz}$ frequency band. These models have been selected due to the availability of correction factors and ease of application.

1) Free space propagation loss: This shows the relationship between the path loss, frequency and distance of the transmission medium (Aragon-Zavala, 2008) as given in (1).

$$
\begin{gathered}
P L(d B)=32.45+20 \log _{10}(d)+20 \log _{10}(f) \\
\text { where } f=\text { frequency in } \mathrm{MHz} \text { and } d=\text { distance in } \mathrm{Km}
\end{gathered}
$$

2) Log-distance pathloss model: The Log-distance pathloss model (Seidel and Rappaport, 1992) is given as shown in (2).

$$
P L(d)=P L\left(d_{o}\right)+10 n \log \left(\frac{d}{d_{o}}\right)
$$

where $P L\left(d_{o}\right)=$ reference pathloss measured at a distance $d_{o}, n=$ pathloss exponent, $d=$ distance between transmitter and receiver (measured in metres), and $d_{o}=$ reference distance (measured in meters).

3) Two-ray pathloss model: The Two-ray pathloss model (Philips et al., 2013) is given as described in (3).

$$
L_{2-\text { ray }}=-10 \log _{10}\left\{\left(\frac{\lambda}{4 \pi d}\right)^{2}\left[2 \sin \left(\frac{2 \pi h_{t} h_{r}}{\lambda d}\right)\right]^{2}\right\}
$$

where $L_{2-\text { ray }}=$ Two-ray propagation loss (measured in $\mathrm{dB}), \lambda=$ Wavelength (measured in metres), $h_{t}=$ Transmitter height (measured in metres), $h_{r}=$ Receiver height (measured in metres), and $d=$ Distance between transmitter and receiver in metres.

4) COST 231-Hata model: The pathloss equation for the COST 231-Hata model (Abhayawardhana et al., 2005; Seybold, 2005) is given in (4).

$$
\begin{gathered}
P L(d B)=46.3+33.9 \log _{10}(f)-13.82 \log _{10} h_{b}- \\
a h_{m}+\left[44.9-6.55 \log _{10}\left(h_{b}\right)\right] \log _{10} d+C_{m}
\end{gathered}
$$

where $f=$ frequency in $\mathrm{MHz}, d=$ distance between transmitter and receiver in $\mathrm{km}, h_{b}=$ base station antenna height above ground level in meters, $h_{r}=$ mobile antenna height in meters.

The correction factor $C_{m}=0 \mathrm{~dB}$ and $3 \mathrm{~dB}$ for suburban and urban environments, respectively. In rural and urban environments, $a h_{m}=\left(1.11 \log _{10} f-0.7\right) h_{r}-$ $\left(1.56 \log _{10} f-0.8\right)$, and $a h_{m}=\left(3.20\left[\log _{10} 11.75 h_{r}\right]^{2}\right)-$ 4.97 for $f \geq 400 \mathrm{MHz}$, for urban environments.

5) Stanford University Interim (SUI) model: The path loss for the Stanford University Interim model (Abhayawardhana et al., 2005; Sulyman et al., 2016) is given in (5).

$$
P_{L}=A+10 \gamma \log \left(\frac{d}{d_{0}}\right)+X_{f}+X_{h}+S d>d_{0}
$$

where, $d$ is the distance between the transmitter and receiver in meters, $d_{0}=100 \mathrm{~m}, X_{f}$ is the frequency correction factor, $X_{h}$ is the base station height correction factor, $A$ is the free space path loss, $\gamma$ is path loss exponent and $S$ is the 
shadowing factor. The path loss exponent from (5) is given in (6).

$$
\gamma=\mathrm{a}-\mathrm{b} h_{b}+\frac{c}{h_{b}}
$$

where $h_{b}$ is the base station height, a, b and $\mathrm{c}$ are terrain factors listed as shown in Table 1.

The free space path loss from (5) is given in (7).

$A=20 \log \left(\frac{4 \pi d_{0}}{\lambda}\right)$

where $d_{0}=$ distance between transmitter and receiver and $\lambda$ is the wavelength in meters.

The correction factor for frequency and base station height for various terrain is given in (8)-(10).

$$
\begin{gathered}
X_{f}=6 \log \left(\frac{f}{2000}\right) \\
X_{h}=-10.8 \log _{10}\left(\frac{h_{r}}{2000}\right) \text { for terrain type A and B } \\
X_{h}=-20 \log _{10}\left(\frac{h_{r}}{2000}\right) \text { for terrain type C }
\end{gathered}
$$

\begin{tabular}{|c|c|c|c|}
\hline Parameters & Terrain A & Terrain B & Terrain C \\
\hline $\mathrm{A}$ & 4.6 & 4.0 & 3.6 \\
\hline $\mathrm{B}(1 / \mathrm{m})$ & 0.0075 & 0.0065 & 0.005 \\
\hline $\mathrm{C}(\mathrm{m})$ & 12.6 & 17.1 & 20 \\
\hline
\end{tabular}

where $f$ is the frequency in $\mathrm{MHz}$ and $h_{r}$ is the height of receiver antenna in meters.

Table 1: Different terrain parameters for the SUI model.

\section{Root mean square error and pathloss exponent}

The mean square error (MSE) helps to determine the error difference between the measured and the predicted pathloss. This is defined as the sum squares of the difference between the measured and the predicted pathloss as given in (11). The square root of the MSE gives the root mean square error given by Ajose and Imoize (2013) as given in (12). In order to determine how rapidly the pathloss varies as the propagation distance between the transmitter and receiver increases, the pathloss exponents of measured data is obtained using (13).

$$
\begin{aligned}
\mathrm{MSE} & =\sum_{i=1}^{N} \frac{\left(P L_{m}-P L_{p}\right)^{2}}{N} \\
\mathrm{MSE} & =\sqrt{\sum_{i=1}^{N} \frac{\left(P L_{m}-P L_{p}\right)^{2}}{N}}
\end{aligned}
$$

where $P L_{m}=$ measured pathloss $(\mathrm{dB}), P L_{p}=$ predicted pathloss (dB), and $N$ is the number of measured data points.

The pathloss exponent $n$ is given in (13).

$n=\frac{\sum_{i=1}^{N} P L_{m}(d)-P L\left(d_{0}\right)}{\sum_{i=1}^{N} 10 \log \frac{d}{d_{0}}}$

where $P L_{m}(d)=$ Measured pathloss $(\mathrm{dB})$ at a distance in $\mathrm{km}, P L\left(d_{0}\right)$ is modeled by free space pathloss given as;

$P L\left(d_{0}\right)=20 \log _{10} \frac{4 \pi d_{0}}{\lambda}$ for the measured scenarios, $d_{0}=$ reference distance taken to be $0.1 \mathrm{~km}, \lambda=$ wavelength in meters.

$$
\text { At } 1800 \mathrm{MHz}, \lambda=\frac{c}{f}=\frac{3 \times 10^{8}}{1800 \times 10^{6}}=0.167 \mathrm{~m} \text {. }
$$
77.6dB.

\section{E. Model optimization}

Model optimization is a process in which a theoretical propagation model is adjusted with the help of measured values obtained from measurement campaigns. The purpose of optimization is to have the predicted path loss values as close as possible to the measured path loss values for the investigated environment. The path loss model selected for optimization (see Section III B) is the COST-231 Hata model, and its mathematical equation (see Subsection II C) given in (4) by Abhayawardhana et al. (2005) and Atanasov and Kissovski (2013).

Equation (4) can be divided into three parts: initial offset parameters, $E_{0}$, the initial system design parameter, $E_{s y s}$, and the slope of the model curve, $\beta_{\text {sys }}$. Thus, from (4), we have:

$$
\begin{aligned}
& E_{0}=46.3-a h_{m}+C_{m} \\
& E_{\text {sys }}=33.9 \log _{10}(f)-13.82 \log _{10} h_{b} \\
& \beta_{\text {sys }}=\left[44.9-6.55 \log _{10}\left(h_{b}\right)\right] \log _{10} d
\end{aligned}
$$

From (14)-(16), Equation (4) can be written as (17).

$$
P L=E_{0}+E_{\text {sys }}+\beta_{\text {sys }}
$$

Now, let $a=E_{0}+E_{s y s} ; b=\beta_{\text {sys }}$, and $P L=P_{r}$. Then, equation (4) can be written as (18),

$$
P_{r}=a+b \log R=a+b x
$$

where $\log R=x, P_{r}=$ predicted pathloss in $\mathrm{dB}, a$ and $b$ are constants for a given set of measured values. Here, best fit of the theoretical model curve with a given set of experimental data would be satisfied by using the least squares algorithm, if the function of sum of deviation squares is minimum as shown in (19).

$$
F(a, b, c, \ldots)=\sum_{i=1}^{N}\left[y_{i}-Q_{R}\left(x_{i}, a, b, c, \ldots\right)\right]^{2}=\min
$$

where $y_{i}=$ measured data at the distance point $x_{i}$, $Q_{R}\left(x_{i}, a, b, c, \ldots\right)=$ modeling result at the $x_{i}$ based on the optimization, $a, b, c=$ parameters of the model based on optimization, $N=$ number of the experimental data set. In order to achieve the least error function $F(a, b, c, \ldots)$, all partial differentials of the function $F$ should be zero as given in (20). The solution to (20) can be expressed as in (21). Repositioning the elements in (21) gives (22).

$$
\begin{aligned}
& \frac{\partial F}{\partial a}=0 ; \frac{\partial F}{\partial b}=0 ; \frac{\partial F}{\partial c}=0 ; \ldots \\
& \sum_{i=1}^{N}\left(y_{i}-Q_{R}\left(x_{i}, a, b, c\right) \frac{\partial P_{r}}{\partial b}\right)=\sum\left(y_{i}-a-b x_{i}\right) \\
& N . a+b \sum x_{i}=\sum y_{i} ; a \sum x_{i}+b \sum x_{i}^{2}=\sum x_{i} y_{i} \\
& \text { Now, the tuned statistical estimates of } \tilde{a} \text { and } \tilde{b} \\
& \text { (23) can be derived by substituting the variables } a \text { a } \\
& \text { a }) . \\
& \tilde{a}=\frac{\sum x_{i}^{2} \cdot \sum y_{i}-\sum x_{i} \sum x_{i} y_{i}}{N \cdot \sum x_{i}^{2}-\left(\sum x_{i}\right)^{2}} ; \tilde{b}=\frac{N \cdot \sum x_{i} y_{i}-\sum x_{i} \sum y_{i}}{N \cdot \sum x_{i}^{2}-\left(\sum x_{i}\right)^{2}}
\end{aligned}
$$$$
\sum_{i=1}^{N}\left(y_{i}-Q_{R}\left(x_{i}, a, b, c\right) \frac{\partial P_{r}}{\partial b}\right)=\sum\left(y_{i}-a-b x_{i}\right) \cdot x_{i}=0
$$

Now, the tuned statistical estimates of $\tilde{a}$ and $\tilde{b}$ as shown in (23) can be derived by substituting the variables $a$ and $b$ into (22).

The tuned statistical elements $\widetilde{a}$ and $\widetilde{b}$ are substituted into the COST 231-Hata model in (17) and the offset parameters can be calculated using (24):

$$
E_{0}=46.3-a h_{m}+C_{m}+R M S E
$$




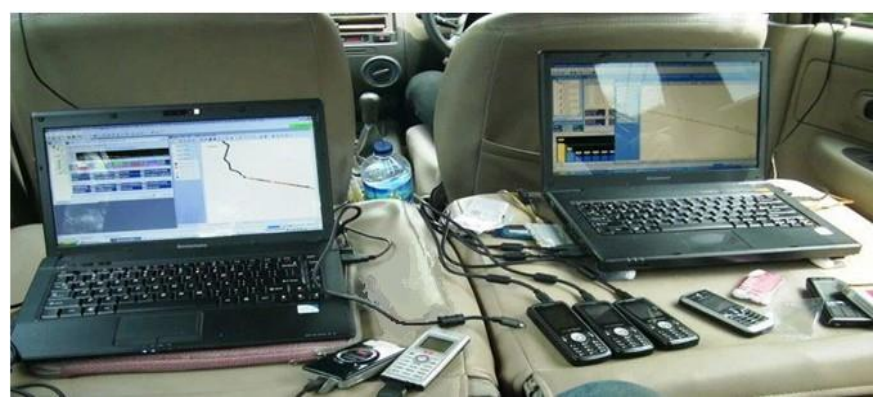

Fig. 1: Experimental setup showing measurement equipment inside a drive test vehicle.

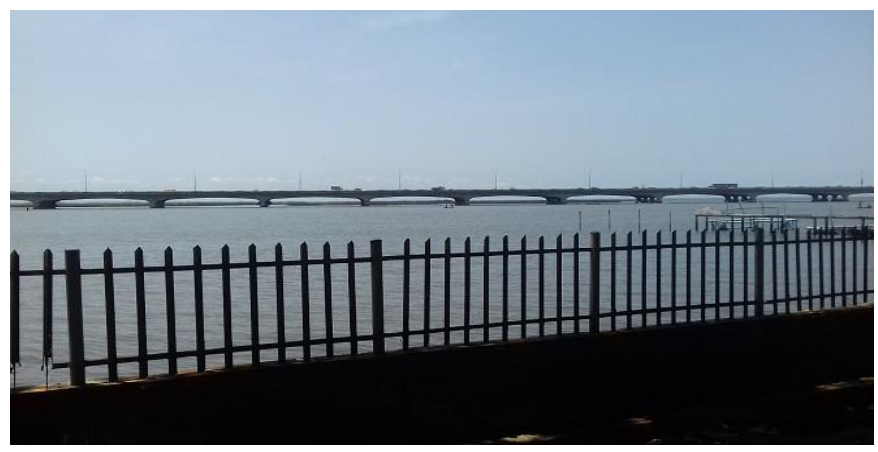

Fig. 2: A pictorial view of the Lagoon environment located at the University of Lagos Nigeria.

\section{ARCHITECTURE OF PROPOSED MODEL}

\section{A. Drive Test Results}

The results of the extensive propagation measurements are as shown in Fig. 3. A comparison of the reference signal received power in $\mathrm{dBm}$, for the initial measurements, measurements after one month, measurements after two months, and measurements after three months is presented. The signal strength for each of the location measured at a distance $d(\mathrm{~km})$ is converted to path loss $P L_{m}(d B)$ given in (25) and (26). The pathloss corresponding to the received power is as shown in Fig. 4, using a similar approach to (Imoize and Dosunmu, 2018).

In addition, a comparison of the measured pathloss and predicted pathloss is as shown in Figs. 5-8 for each scenario. In order to determine the best-fit model, the RMSEs between the measured and predicted pathloss is calculated as shown in Table 2. In order to know how rapidly the pathloss varies with respect to the propagation distance, the pathloss exponents of measured data was obtained using (3). For $N=22$, the value of $77.6 \mathrm{~dB}$ was used in the pathloss exponent formula given in (3) for each distance interval, $d$. The calculated pathloss exponents for all measurements are as shown in Table 3.

The pathloss exponents are seen to compare fairly with the values reported in (Feuerstein et al., 1994). From the comparative analysis, it was found that the COST 231-Hata model showed the most accurate performance. This was optimized using the least squares algorithm with parameters as outlined in Table 4 and Table 5. A comparison of the measured pathloss, predicted, and the optimized COST 231Hata model for the initial measurements, after one-month measurements, after two months measurements, and after three months measurements, are as shown in Figs. 9-12, respectively. Finally, a test for the validity of the optimized model was presented by calculating the RMSEs between the measured pathloss and optimized pathloss model, and lower values of RMSEs indicate that the optimized model is valid. A comparison of the RMSEs between the original COST 231Hata, and the optimized COST 231-Hata models is as shown in Table 6.

$$
P L_{m}(d B)=E I R P_{t}(d B m)-P_{r}(d B m)
$$

where $\quad E I R P_{t}=$ Effective isotropic radiated power in $\mathrm{dBm}, P_{r}=$ Mean reference signal received power (RSRP). The effective isotropic radiated power $E I R P_{t}$ is given as:

$$
E I R P_{t}=P_{T}+G_{T}-L_{T}
$$

where $P_{T}=$ Transmitter power in $\mathrm{dBm}, G_{T}=$ Transmitter antenna gain in $\mathrm{dBi}, L_{T}=$ Total Transmission Losses in $\mathrm{dB}$. The values of the transmitter power, transmitter antenna gain and the total transmission loss are given;

$$
P_{T}=43 \mathrm{dBm}, G_{T}=18 \mathrm{dBi}, L_{T}=22 \mathrm{~dB} \text {. Substituting }
$$
these values into (17) gives (27).

$$
E I R P_{t}=43+18-22=39 \mathrm{dBm} \text {. }
$$

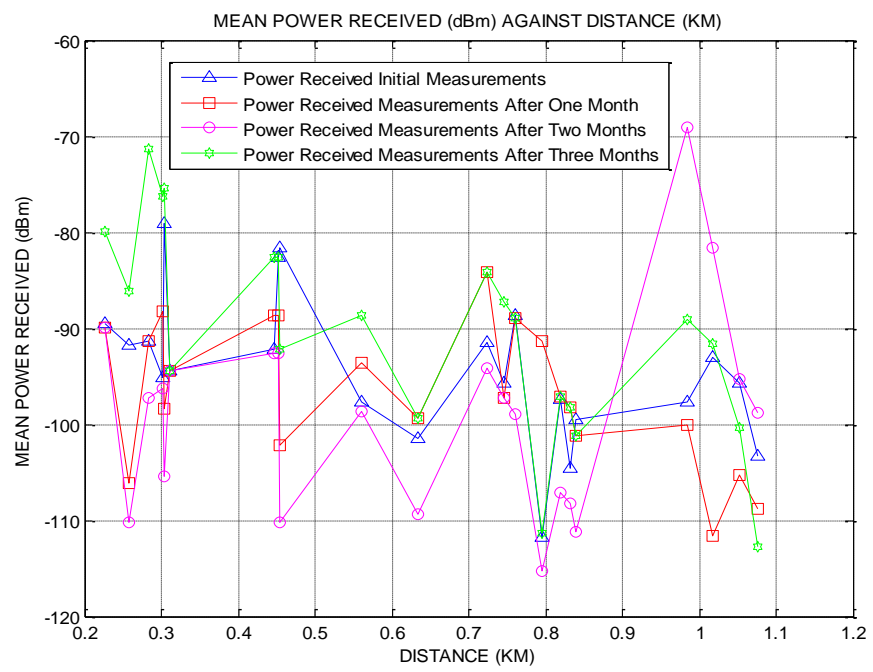

Fig. 3: Reference signal received power of measured data at different measurement scenarios.

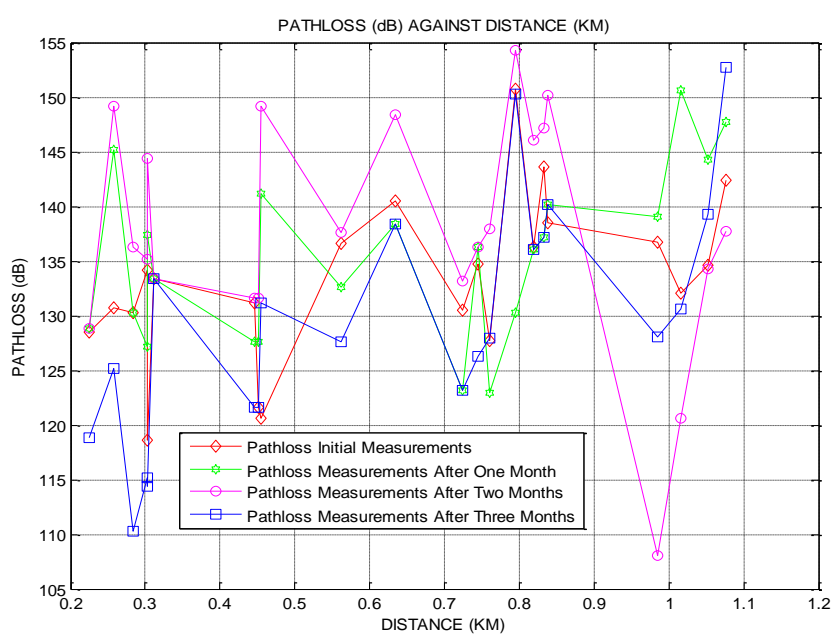

Fig. 4: Pathlosses of measured data at different measurement scenarios. 


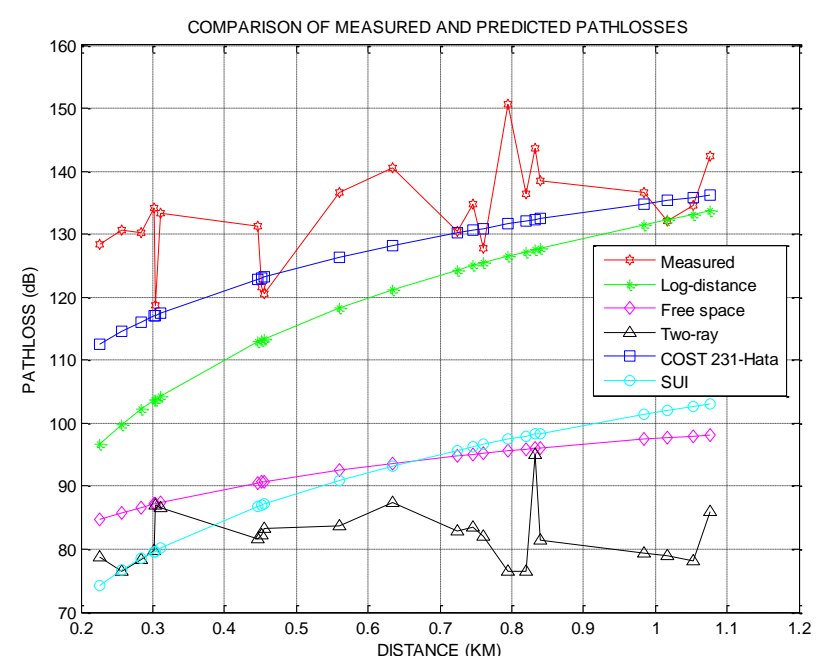

Fig. 5: Comparison of measured pathlosses with five models' predicted pathlosses for initial measurements.

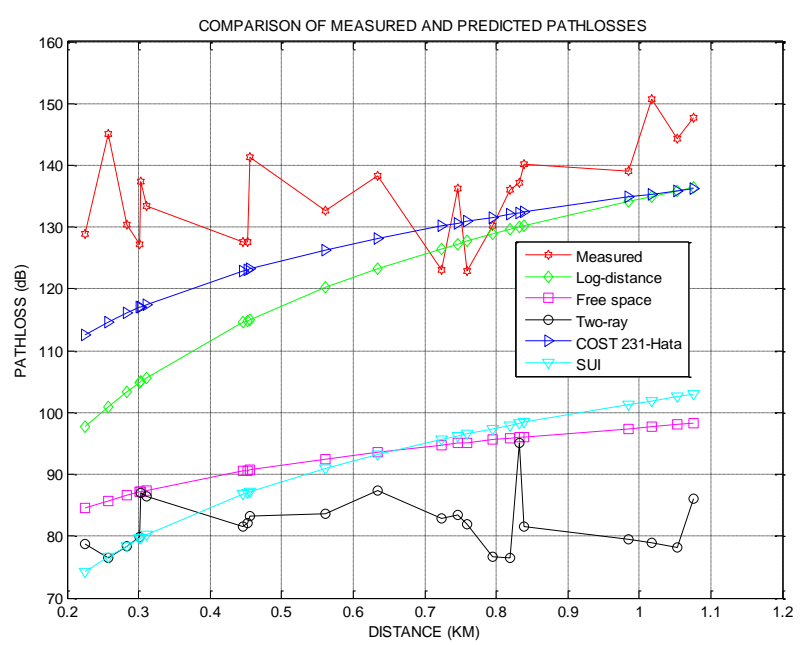

Fig. 6: Comparison of measured pathlosses with five models' predicted pathlosses for measurements after one month.

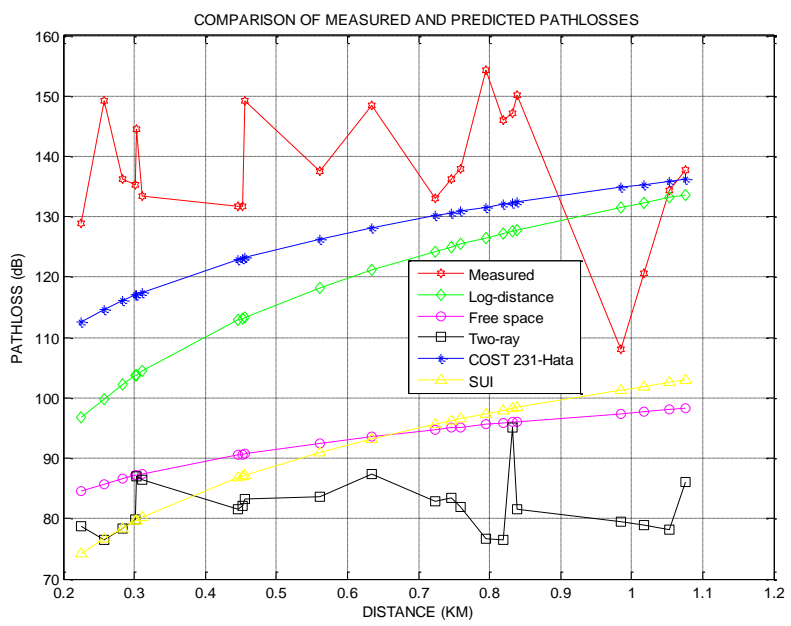

Fig. 7: Comparison of measured pathlosses with five models' predicted pathlosses for measurements after two months.

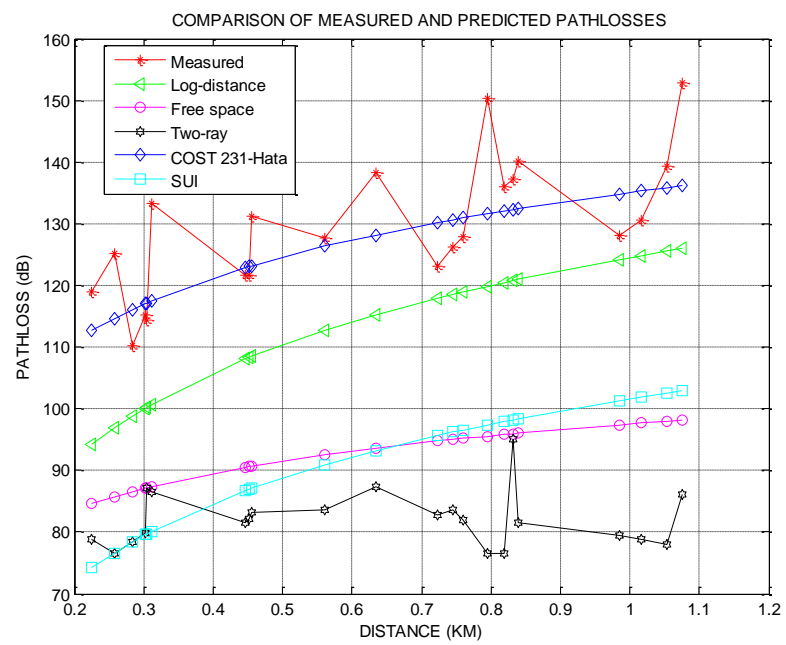

Fig. 8: Comparison of measured pathlosses with five models' predicted pathlosses for measurements after three months.

Table 2: Root Mean Square Errors (RMSEs).

\begin{tabular}{lccccc}
\hline $\begin{array}{l}\text { Measurement } \\
\text { Scenario }\end{array}$ & $\begin{array}{c}\text { Free } \\
\text { space } \\
(\mathbf{d B})\end{array}$ & $\begin{array}{c}\text { Log- } \\
\text { distance } \\
(\mathbf{d B})\end{array}$ & $\begin{array}{c}\text { Two- } \\
\text { ray } \\
(\mathbf{d B})\end{array}$ & $\begin{array}{c}\text { COST } \\
\text { 231-Hata } \\
(\mathbf{d B})\end{array}$ & $\begin{array}{c}\text { SUI } \\
(\mathbf{d B})\end{array}$ \\
\hline $\begin{array}{l}\text { Initial } \\
\text { measurements }\end{array}$ & 41.32 & 13.61 & 51.77 & 10.03 & 38.75 \\
$\begin{array}{l}\text { Measurements } \\
\text { after one month }\end{array}$ & 43.44 & 9.25 & 53.61 & 12.38 & 40.78 \\
$\begin{array}{l}\text { Measurements } \\
\text { after two }\end{array}$ & 46.77 & 25.49 & 56.86 & 17.59 & 43.88 \\
$\begin{array}{l}\text { months } \\
\begin{array}{l}\text { Measurements } \\
\text { after three } \\
\text { months }\end{array}\end{array}$ & 36.63 & 3.87 & 47.24 & 7.67 & 34.3 \\
\hline
\end{tabular}

\section{B. Best model selection}

In order to determine the best model for pathloss prediction in the investigated environment, the root mean square error (RMSE) method was used to determine the error between the measured and the predicted model. The model with the least RMSE gives the best prediction. Here, the COST 231-Hata model showed the best performance. It showed the most accurate performances as revealed in Figs. 5-8 for the initial measurements, measurements after one month, measurements after two months, and measurements after three months, with RMSEs of $10.03 \mathrm{~dB}, 12.38 \mathrm{~dB}, 17.59 \mathrm{~dB}$, and $7.67 \mathrm{~dB}$, respectively. Therefore, the COST-231 Hata model was selected as the best model for path loss prediction in the investigated environment.

Table 3: Pathloss exponents of measured data.

\begin{tabular}{lc}
\hline Measurement Scenario & Pathloss exponent $(\boldsymbol{n})$ \\
\hline Initial measurements & 5.4 \\
Measurements after one month & 5.7 \\
Measurements after two months & 5.4 \\
Measurements after three months & 4.7 \\
\hline
\end{tabular}


Table 4: Calculated model parameters.

\begin{tabular}{cc}
\hline Parameters & Values \\
\hline $\boldsymbol{E}_{\mathbf{0}}$ & $46.3-a h_{m}+C_{m}$ \\
$\boldsymbol{E}_{\boldsymbol{s y s}}$ & 88.85 \\
$\boldsymbol{a}$ & 135.10 \\
$\boldsymbol{b}$ & 34.71 \\
$\boldsymbol{E}_{\mathbf{0} \text { new }}$ & $46.3-a h_{m}+C_{m}+R M S E$ \\
\hline
\end{tabular}

Table 5: New offset parameters for measured data.

\begin{tabular}{lc}
\hline Measurement Scenario & $\boldsymbol{E}_{\mathbf{0} \text { new }}$ \\
\hline Initial measurements & $56.33-a h_{m}+C_{m}$ \\
Measurements after one month & $58.68-a h_{m}+C_{m}$ \\
Measurements after two months & $63.89-a h_{m}+C_{m}$ \\
Measurements after three months & $53.97-a h_{m}+C_{m}$ \\
\hline
\end{tabular}

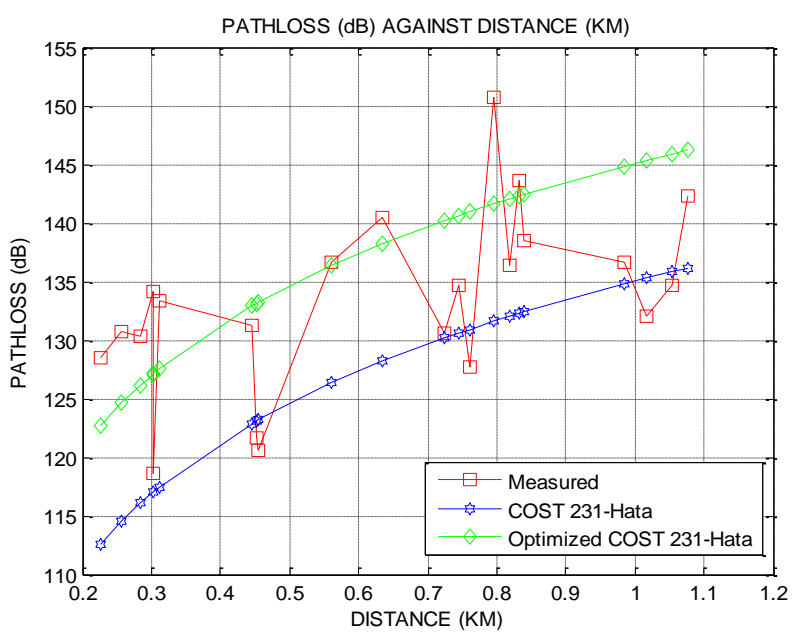

Fig. 9: Optimized COST 231 Hata model for initial measurements.

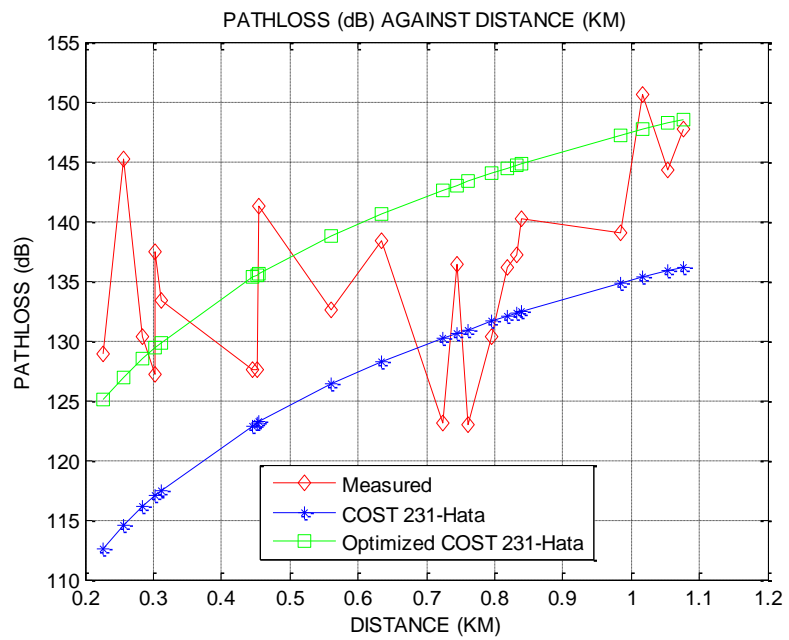

Fig. 10: Optimized COST 231 Hata model for measurements after one month.

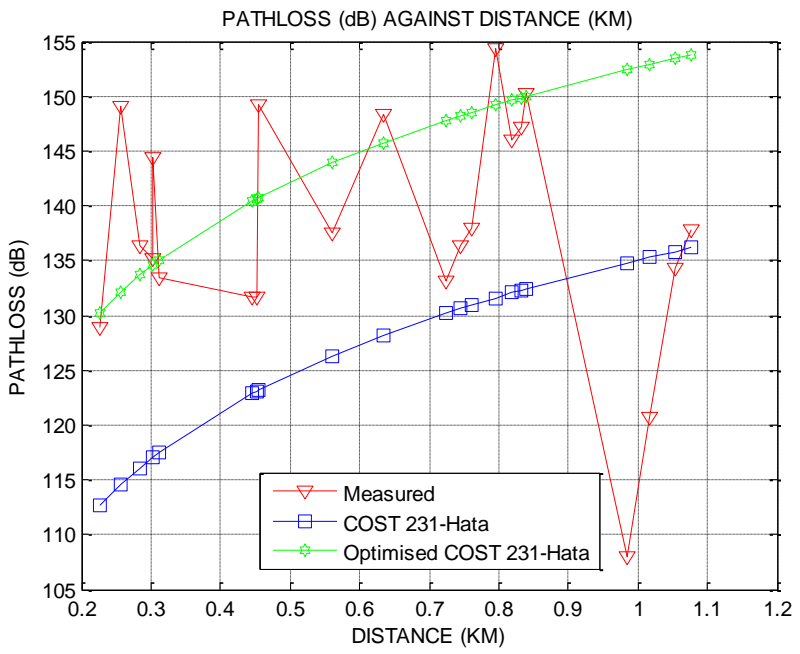

Fig. 11: Optimized COST 231 Hata model for measurements after two months.

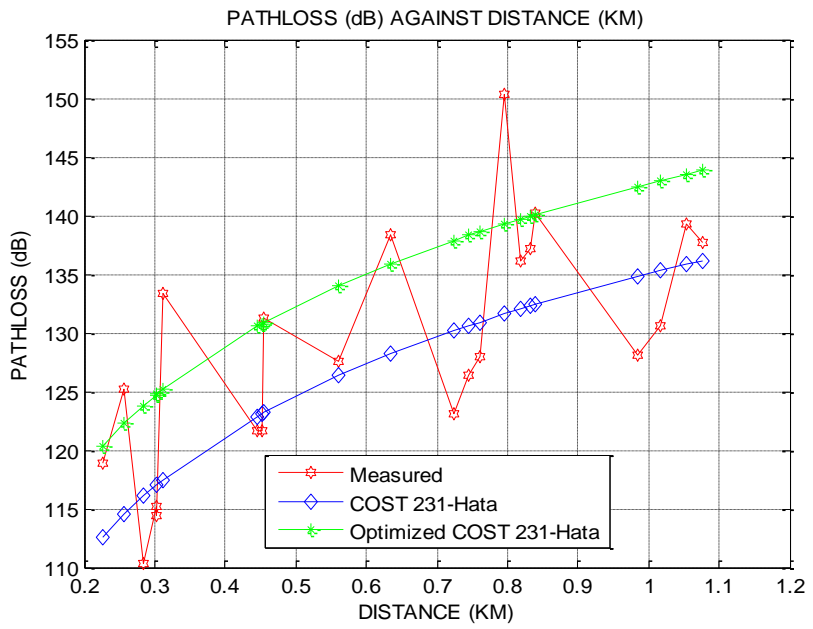

Fig. 12: Optimized COST 231 Hata model for measurements after three months.

\section{Validation of the optimized model}

How do we know whether the optimized model is valid? In order to answer this question, a test for the validity of the optimized model was carried out as follows. First, the root mean square error (RMSE) between the measured data and the optimized model was obtained. According to $\mathrm{Wu}$ and Yuan (1998), RMSEs closer to zero indicate improvements in the model. Here, the optimized model showed lower RMSEs compared with the actual COST 231-Hata model for the tested scenarios. A significant reduction in the RMSEs is an indication that the optimized model is valid. A comparison of the RMSEs obtained for the COST 231-Hata and the optimized COST 231-Hata models is as shown in Table 6. As presented in the table, the average RMSE is given by (27). By using higher order polynomials, the equations depicting the optimized model in Figs. 9-12 for the initial measurements, measurements after one month, measurements after two 
months, and measurements after three months are given in (28)-(31), respectively.

$$
R M S E_{\text {ave }}=\frac{\sum_{i=0}^{N} R M S E_{i}}{N}=\frac{R M S E_{0}+R M S E_{1}+R M S E_{2}+R M S E_{3}}{4}
$$

For the COST 231-Hata model, $R M S E_{\text {ave }}=11.92 \mathrm{~dB}$ and $R M S E_{\text {ave }}=9.32 \mathrm{~dB}$ for the Optimized COST 231-Hata model.

$$
\begin{aligned}
& P L_{0}(d B)=-367.82 d^{10}+2650.2 d^{9}-8512.8 d^{8}+ \\
& 16083 d^{7}-19858 d^{6}+16842 d^{5}-10047 d^{4}+ \\
& 4255.4 d^{3}-1289.6 d^{2}+298.9 d+90.361 \\
& P L_{1}(d B)=-367.82 d^{10}+2650.2 d^{9}-8512.8 d^{8}+ \\
& 16083 d^{7}-19858 d^{6}+16842 d^{5}-10047 d^{4}+ \\
& 4255.4 d^{3}-1289.6 d^{2}+298.9 d+92.711 \\
& \quad P L_{2}(d B)=-367.82 d^{10}+2650.2 d^{9}-8512.8 d^{8}+ \\
& 16083 d^{7}-19858 d^{6}+16842 d^{5}-10047 d^{4}+ \\
& 4255.4 d^{3}-1289.6 d^{2}+298.9 d+97.921 \\
& \quad P L_{3}(d B)=-367.82 d^{10}+2650.2 d^{9}-8512.8 d^{8}+ \\
& 16083 d^{7}-19858 d^{6}+16842 d^{5}-10047 d^{4}+ \\
& 4255.4 d^{3}-1289.6 d^{2}+298.9 d+80.001 \\
& \quad \text { where } P L_{0}(d B), P L_{1}(d B), P L_{2}(d B) \text { and } P L_{3}(d B) \text { are } \\
& \text { pathlosses for the initial measurements, measurements after } \\
& \text { one month, measurements after two months, and } \\
& \text { measurements after three months, respectively and } d \text { is } \\
& \text { propagation distance in metres. }
\end{aligned}
$$

Table 6: RMSEs Comparison of the actual and optimized COST 231Hata model.

\begin{tabular}{lcc}
\hline Measurement Scenario & $\begin{array}{c}\text { COST 231- } \\
\text { Hata model } \\
(\mathbf{d B})\end{array}$ & $\begin{array}{c}\text { Optimized COST 231- } \\
\text { Hata model (dB) }\end{array}$ \\
\hline $\begin{array}{l}\text { Initial measurements } \\
\begin{array}{l}\text { Measurements after one } \\
\text { month }\end{array}\end{array}$ & 10.03 & 7.90 \\
$\begin{array}{l}\text { Measurements after two } \\
\text { months }\end{array}$ & 12.38 & 9.28 \\
$\begin{array}{l}\text { Measurements after three } \\
\text { months }\end{array}$ & 7.67 & 14.82 \\
Average RMSEs & 11.92 & 5.28 \\
& & 9.32 \\
\hline
\end{tabular}

\section{Discussion}

Initial results showed that the COST 231- Hata model provided the most accurate pathloss prediction among the contending models. This model gave prediction errors of 10.03 $\mathrm{dB}, 12.38 \mathrm{~dB}, 17.59 \mathrm{~dB}$, and $7.67 \mathrm{~dB}$ for the initial measurements, measurements after one month, measurements after two months, and measurements after three months, respectively. However, these root mean square errors (RMSEs) are relatively high and there is a need to optimize the model in order to improve its prediction accuracy. Therefore, the COST 231- Hata model was optimized and the optimized model showed improved RMSEs of $7.90 \mathrm{~dB}, 9.28 \mathrm{~dB}, 14.82 \mathrm{~dB}$, and $5.28 \mathrm{~dB}$ for the initial measurements, measurements after one month, measurements after two months, and measurements after three months, respectively.

For the original COST 231-Hata model as shown in Table 6 , the RMSEs obtained for the measurements after one month, and measurements after two months are higher compared with the initial measurements and measurements after three months. Perhaps, this is expected due to the circumstances and conditions under which these measurements were taken. Generally, there was heavy rainfall in those two months, and heavy rainfall subsequently caused an increase in the level of the water in the Lagoon, which in turn affected the quality of the signal received from the measured eNodeBs. However, these results compare favourably with the results reported in a related work (Ju et al., 2017).

\section{CONCLUSION}

This study was focused on optimization of a best-fit propagation model for improved pathloss prediction of a $4 \mathrm{G}$ LTE network in a Lagoon environment. Measured pathloss was compared with predicted pathloss at $1800 \mathrm{MHz}$. The COST 231-Hata model was found to be most accurate for the Lagoon environment and an optimized COST 231-Hata model has been evolved and found satisfactory for the environment. The optimized model could be very useful to network planners and engineers for network planning, to enhance network quality in a similar environment. Future studies could extend the measurements period to possibly a year or more. This would help to validate the suitability of the proposed model for path loss prediction in related environments. In addition, the impact of different frequency bands on the optimized model need further investigation.

\section{REFERENCES}

Abhayawardhana, V. S.; I. J. Wassell, D. Crosby, M. P. Sellars, and M. G. Brown. (2005, May). Comparison of empirical propagation path loss models for fixed wireless access systems. In IEEE 61st Vehicular Technology Conference, Stockholm, Sweden, 1:73-77.

Ajose, S. O., and Imoize, A. L. (2013). Propagation measurements and modelling at $1800 \mathrm{MHz}$ in Lagos Nigeria. International Journal of Wireless and Mobile Computing, 6(2):165-174.

Aragon-Zavala, A. (2008). Antennas and propagation for wireless communication systems. John Wiley \& Sons.

Atanasov, P., and Kissovski, Z. (2013). Investigations of the Signal Path Loss in 4G LTE Network. Bulgaria Journal of Physics, 40: 265-268.

Erceg, V.; L. J. Greenstein, S. Y. Tjandra, S. R. Parkoff, A. Gupta, B. Kulic, A. A. Julius, and R. Bianchi. (1999). An empirically based path loss model for wireless channels in suburban environments. IEEE Journal on Selected Areas in Communications, 17(7):1205-1211.

Feuerstein, M. J.; K. L. Blackard, T. S. Rappaport, S. Y. Seidel, and H. H. Xia. (1994). Path loss, delay spread, and outage models as functions of antenna height for microcellular system design. IEEE Transactions on Vehicular Technology, 43(3):487-498.

Hata, M., (1980). Empirical formula for propagation loss in land mobile radio services. IEEE Transactions on Vehicular Technology, 29(3):317-325.

Ibhaze, A. E.; A. L. Imoize, S. O. Ajose, S. N. John, C. U. Ndujiuba, and F. E. Idachaba. (2017). An Empirical Propagation Model for Path Loss Prediction at $2100 \mathrm{MHz}$ in a Dense Urban Environment. Indian Journal of Science and Technology, 10(5):1-9.

Imoize, A. L., and Dosunmu, A. I. (2018). Pathloss Characterization of Long Term Evolution Network for Lagos, 
Nigeria. Jordan Journal of Electrical Engineering, 4(2):114128.

Karasawa, Y.; T. Kuroda, and H. Iwai. (1997). The equivalent transmission-path model-a tool for analyzing error floor characteristics due to intersymbol interference in Nakagami-Rice fading environments. IEEE Transactions on Vehicular Technology, 46(1):194-202.

Milanovic, J.; S. Rimac-Drlje, and K. Bejuk (2007). Comparison of propagation models accuracy for WiMAX on 3.5 GHz. In 14th IEEE International Conference on Electronics, Circuits and Systems (ICECS), 11-14 December 2007, Marrakech, Morocco, 111-114. DOI: 10.1109/ICECS.2007.4510943.

Phillips, C.; D. Sicker, and D. Grunwald. (2013). A survey of wireless path loss prediction and coverage mapping methods. IEEE Communications Surveys and Tutorials, 15(1):255-270.

Rappaport, T. S. (1996). Wireless communications: principles and practice, New Jersey: Prentice Hall PTR.

Reyes-Guerrero, J. C.; M. Bruno, L. A. Mariscal, and A. Medouri. (2011, September). Buoy-to-ship experimental measurements over sea at $5.8 \mathrm{GHz}$ near urban environments. In $11^{\text {th }}$ IEEE Mediterranean Microwave Symposium (MMS), 8-10 September 2011, Yasmine Hammamet, Tunisia, 320-324. DOI: 10.1109/MMS.2011.6068590.

Saxena, A., and Sindal, R. (2018). An Optimized LTE Hand over Model on Quality and Margin with Key Performance Indicator. Wireless Personal Communications, 98(2):2389-2401.

Sharma, P. K., and Singh, R. K. (2010). Comparative analysis of propagation path loss models with field measured data. International Journal of Engineering Science and Technology, 2(6):2008-2013.

Sharma, P. K.; D. Sharma, P. C. Sau, and A. Gupta. (2016, November). Comparative analysis of propagation models in LTE networks with spline interpolation. In $2^{\text {nd }}$ IEEE International Conference on Communication Control and Intelligent Systems (CCIS), 18-20 November 2016, Mathura, India, 3-7. DOI: 10.1109/CCIntelS.2016.7878189.

Seidel, S. Y., and Rappaport, T. S. (1992). $914 \mathrm{MHz}$ path loss prediction models for indoor wireless communications in multi-floored buildings. IEEE Transactions on Antennas and Propagation, 40(2): 207-217.
Seybold, J. S. (2005). Introduction to RF propagation. John Wiley \& Sons.

Sulyman, A. I.; A. Alwarafy, G. R. MacCartney, T. S. Rappaport, and A. Alsanie. (2016). Directional radio propagation path loss models for millimeter-wave wireless networks in the 28-, 60-, and $73-\mathrm{GHz}$ bands. IEEE Transactions on Wireless Communications, 15(10): 69396947.

Ubom, E. A.; V. E. Idigo, A. C. O. Azubogu, C. O. Ohaneme, and T. L. Alumona. (2011). Path loss characterization of wireless propagation for South-South region of Nigeria. International Journal of Computer Theory and Engineering, 3(3): 478-482.

Wang, W.; G. Hoerack, T. Jost, R. Raulefs, M. Walter, and U. C. Fiebig. (2015). Scattering Phenomena of the Propagation Channel at $5.2 \mathrm{GHz}$ on the Baltic Sea. In $9^{\text {th }}$ IEEE European Conference on Antenna and Propagation (EuCAP), 13-17 April 2015, Lisbon, Portugal, 1-5.

Weissberger, M. A. (1982). An initial critical summary of models for predicting the attenuation of radio waves by trees. Electromagnetic Compatibility Analysis Center, Annapolis, MD. ESD-TR-81-101: 1-162.

Wu, J., and Yuan, D. (1998, September). Propagation measurements and modeling in Jinan city. In Personal, Indoor and Mobile Radio Communications, In 9th IEEE International Symposium on Personal, Indoor and Mobile Radio Communications, 8-11 September 1998, Boston, Massachusetts USA, 3: 1157-1160. DOI: 10.1109/PIMRC.1998.731360.

Yee Hui, L. E. E.; F. Dong, and Y. S. Meng. (2014). Near sea-surface mobile radiowave propagation at $5 \mathrm{GHz}$ : measurements and modeling. Radioengineering, 23(3): 824830.

Yu, J.; W. Chen, K. Yang, C. Li, F. Li, and Y. Shui. (2017). Path loss channel model for inland river radio propagation at $1.4 \mathrm{GHz}$. International Journal of Antennas and Propagation, 1-15. DOI: 10.1155/2017/5853724

Zhou, M. T.; J. Jurianto, J. S. Pathmasuntharam, and M. Fujise. (2006, November). Characterization of radio path loss in seaport environment for WiMAX applications. In Proceeding of International Symposium on Antennas and Propagation (ISAP), 2-4 November 2006, National University of Singapore, Singapore, 1-4. 